\title{
Toxicidade de Filtrados de Cultura de Alternaria euphorbiicola EM FOLHAS DE Euphorbia heterophylla
}

\author{
Phytotoxicity of Alternaria euphorbiicola Culture Filtrates in Euphorbia heterophylla Leaves
}

VAREJÃO, E.V.V. ${ }^{2}$, DEMUNER, A.J. ${ }^{3}$, BARBOSA, L.C.A. ${ }^{4}$, BARRETO, R.W. ${ }^{5}$ e VIEIRA, B.S. ${ }^{6}$

\begin{abstract}
RESUMO - A espécie fúngica Alternaria euphorbiicola é agente causal de severas necroses de inflorescência, queimas de folhas e cancros da haste em Euphorbia heterophylla (leiteiro ou amendoim-bravo), importante planta daninha responsável por grandes prejuízos à agricultura brasileira. A aplicação de suspensões de esporos do fungo sobre populações da planta hospedeira resulta em rápida produção de necrose dos tecidos das plantas (24 a 48 horas após aplicação). Essas observações levaram à conjectura de que o fungo possa produzir fitotoxinas in vitro capazes de causar lesão às plantas. O objetivo deste trabalho foi investigar preliminarmente a produção in vitro de fitotoxinas por $A$. euphorbiicola sob diferentes condições de cultivo. Os resultados mostraram que a composição do meio de cultura e as condições de cultivo influenciaram a fitotoxicidade de filtrados de cultura, tendo o cultivo sob agitação e na ausência de luz favorecido a produção de metabólitos fitotóxicos pelo fungo. O filtrado da cultura em meio de Jenkins-Prior modificado, crescida sob agitação, no escuro e a $28^{\circ} \mathrm{C}$, apresentou a maior atividade fitotóxica, tendo produzido extensas necroses foliares e desfolha em plantas de E. heterophylla. Esse filtrado de cultura foi submetido a extração seguida por fracionamento guiado por bioensaios. Uma fração cromatográfica constituída majoritariamente por ácidos graxos de cadeia longa produziu halos cloróticos e necrose de folhas, assim como observado após a inoculação de E. heterophylla com o fungo. Esses resultados sugerem a participação de ácidos graxos no processo infeccioso na associação A. euphorbiicola $\mathrm{x}$ E. heterophylla.
\end{abstract}

Palavras-chave: Ascomycota, fungo, amendoim-bravo, Euphorbia heterophylla, fitotoxinas, isolamento guiado por bioensaio.

\begin{abstract}
The fungal species Alternaria euphorbiicola was identified as causal agent of inflorescence necrosis, leaf blight, and stem cancer in Euphorbia heterophylla (wild poinsettia), a major weed responsible for great agricultural losses in Brazil. The application of spore suspensions of the fungus on specimens of the host plant resulted in production of disseminated necrosis at short time intervals (24 to 48 hours) after application. These observations led to the hypothesis that the fungus could produce phytotoxins capable of causing damage to the plant. The objective of this study was to investigate the in vitro production of phytotoxins by $\boldsymbol{A}$. euphorbiicola under different growth conditions. The results showed that the culture medium and growth conditions influenced the phytotoxicity of the culture filtrates. Growing the fungus under agitation in the dark resulted in higher production of phytotoxic metabolites. The filtrate from the culture formed in modified JenkinsPrior medium, under agitation, at $28^{\circ} \mathrm{C}$ in the dark showed the highest phytotoxic activity. This filtrate produced foliarnecrosis and defoliation in $\boldsymbol{E}$. heterophylla and was subjected to extraction followed by bioassay-guided fractionation. A chromatographic fraction consisting mainly of longchain fatty acids produced bleached lesions and necrosis of the leaves, the same symptoms observed after inoculation of the fungus in the host plant. These results suggest the involvement of these phytotoxic fatty acids in the process of tissue invasion of $\boldsymbol{E}$. heterophylla by A. euphorbiicola.
\end{abstract}

Keywords: Ascomycota, fungus, wild poinsettia, Euphorbia heterophylla, phytotoxins, bioassay-guided fractionation.

Recebido para publicação em 2.3.12 e aprovado em 20.8.12

2 Pesquisador, D.Sc., Dep. de Química, Universidade Federal de Viçosa - DEQ/UFV, <eduardo@varejao.org>; ${ }^{3}$ Professor, D.Sc., DEQ/UFV; ${ }^{4}$ Professor, Ph.D., DEQ/UFV; ${ }^{5}$ Professor, Ph.D., Dep. de Fitopatologia - DFP/UFV; ${ }^{6}$ Professor, D.Sc., Instituto de Ciências Agrárias, Universidade Federal de Uberlândia - UFU.

Planta Daninha, Viçosa-MG, v. 31, n. 1, p. 1-9, 2013 


\section{INTRODUÇÃO}

O leiteiro ou amendoim-bravo, Euphorbia heterophylla, é uma planta daninha altamente competitiva, considerada uma das principais invasoras nas culturas da soja e do feijão (Rizzardi et al., 2004; Carvalho et al., 2010; Cury et al., 2011).

O controle de infestações de $E$. heterophylla vem sendo exercido principalmente com o uso de herbicidas inibidores da enzima acetolactato sintase (ALS). Entretanto, o uso repetitivo desses herbicidas levou à seleção de populações resistentes (Gazziero et al., 1998), como, por exemplo, a ocorrência de biótipos resistentes ao glifosato (Vidal et al., 2007; Cerdeira et al., 2011) e o surgimento de biótipos com múltipla resistência a herbicidas inibidores da ALS e inibidores da protoporfirinogênio oxidase (PROTOX) (Trezzi et al., 2005). Diante desse quadro, torna-se de grande interesse a busca por novos compostos químicos para o manejo de E. heterophylla.

Durante trabalhos de levantamento de fungos fitopatogênicos associados a plantas daninhas relevantes no Brasil, a espécie Alternaria euphorbiicola foi isolada a partir de tecidos severamente infectados de Euphorbia heterophylla (Barreto \& Evans, 1998). Durante estudos sobre o potencial de $A$. euphorbiicola como agente para o controle biológico de E. heterophylla, foi observado que a aplicação de suspensões de esporos do fungo sobre populações da planta hospedeira resulta em rápida produção de necrose de tecidos $(24$ a 48 horas após aplicação). Esse período seria insuficiente para os processos de germinação de esporos, penetração de tecidos, colonização e desenvolvimento de sintomas resultantes da infecção. Essas observações levaram à conjectura de que o fungo produz, antes mesmo da colonização da planta, fitotoxinas capazes de provocar necroses em $E$. heterophylla.

A produção de metabólitos fitotóxicos por fungos fitopatogênicos e a capacidade desses compostos de causar lesões em tecidos da planta hospedeira encontram-se amplamente descritas na literatura (Demuner et al., 2006; Strange, 2007; Möbius \& Hertweck, 2009). Fatores como a diversidade estrutural e a capacidade de produzir efeitos fitotóxicos em pequenas concentrações e de atuar por novos mecanismos de ação fazem com que fitotoxinas fúngicas sejam consideradas uma fonte promissora para a produção de novos herbicidas naturais (Hoagland, 2001; Duke et al., 2002). Ainda que não apresentem propriedades adequadas para o uso direto, esses compostos mostram grande potencial como modelos para a sintese de novos herbicidas (Barbosa et al., 2003; Chaves et al., 2006; Barbosa et al., 2009).

A investigação da produção de fitotoxinas por fungos fitopatogênicos normalmente inicia-se com a avaliação da fitotoxicidade de filtrados de cultura livres de células. Após o período de incubação, o meio de cultura é submetido à filtração, sendo o filtrado avaliado em ensaios para demonstração de fitotoxicidade (Chen \& Swart, 2002; Souza Filho \& Duarte, 2007). Estudos sobre a possivel influência das condições de crescimento sobre a fitotoxicidade de filtrados de cultura podem ser conduzidos, de modo que as condições mais favoráveis para a produção de fitotoxinas sejam utilizadas para fins de produção, extração, fracionamento e caracterização de compostos químicos fitotóxicos (Berestetskyi, 2008).

A agressividade e rapidez no desenvolvimento de sintomas por A. euphorbiicola contra $E$. heterophylla despertaram o interesse pelo isolamento, identificação e avaliação de compostos fitotóxicos produzidos pelo fungo como candidatos a agentes naturais para controle químico de E. heterophylla. Neste trabalho foi investigada a fitotoxicidade de filtrados de cultura de $A$. euphorbiicola produzidos sob diferentes condições de cultivo.

\section{MATERIAL E MÉTODOS}

Procedimentos gerais: extrações e procedimentos cromatográficos foram realizados utilizando-se solventes de grau analítico. As separações cromatográficas em coluna foram feitas usando-se sílica-gel 60 (70-230 mesh). Para cromatografia em camada delgada analítica, foram utilizadas placas de sílica-gel $60 \mathrm{~F}_{254} \operatorname{com} 0,25 \mathrm{~mm}$ de espessura e revelação com luz ultravioleta (254 e $366 \mathrm{~nm}$ ), seguida por nebulização com solução alcoólica de ácido fosfomolíbdico. Os espectros na região do infravermelho (IV) foram obtidos em espectrômetro Varian FT-IR 660-IR, equipado com acessório 
Pike GladiATR. As análises por cromatografia a gás acoplada a espectrometria de massas foram realizadas em equipamento Shimadzu GCMS-QP5050A, nas seguintes condições operacionais: método por impacto de elétrons (70 eV); modo scan, $\mathrm{m} / \mathrm{z}$ 30,00 a 700,00; coluna capilar RTx5 (30 m x 0,25 mm, 0,25 $\mu \mathrm{m}$ ); fluxo do gás de arraste $(\mathrm{He})$ de $1 \mathrm{~mL}$ min $^{1}$; razão de split 1:5; programação de temperatura: $\mathrm{T}_{1}=$ $40{ }^{\circ} \mathrm{C}$ por $5 \mathrm{~min}$, gradiente de $4{ }^{\circ} \mathrm{C} \mathrm{min}^{-1}$ até $\mathrm{T}_{2}=80^{\circ} \mathrm{C}$ e gradiente de $10^{\circ} \mathrm{C} \mathrm{min}^{-1}$ até $\mathrm{T}_{3}=$ $285^{\circ} \mathrm{C}$; temperatura do injetor de $290{ }^{\circ} \mathrm{C}$; e temperatura do detector de $290{ }^{\circ} \mathrm{C}$. Os constituintes químicos foram identificados por comparação dos espectros de massas com aqueles existentes no banco de dados do equipamento e pelo indice de kovat's (Linstrom \& Mallard, 2005).

Cultivo do fungo: Alternaria euphorbiicola (isolado KLN 06), originalmente isolado de tecidos infectados de E. heterophylla, foi cultivado em placas de Petri contendo meio de cultura Caldo de Vegetais-Ágar (Pereira et al., 2003) a $25^{\circ} \mathrm{C}$ por sete dias. Discos de micélio $(\varnothing=10 \mathrm{~mm})$ provenientes da periferia de culturas em crescimento ativo foram assepticamente repicados para frascos erlenmeyers de $2 \mathrm{~L}$, contendo, cada um, $300 \mathrm{~mL}$ de diferentes meios de cultura líquidos: Caldo de Vegetais (Pereira et al., 2003); meio de Jenkins-Prior modificado (Fargues et al., 2001); Czapek-Dox; e meio de Fries (Beadle \& Tatum, 1941). Para investigação da possivel interferência das condições de cultivo na produção de compostos fitotóxicos pelo fungo, foram utilizadas as seguintes condições: $A$, cultivo sob agitação a $150 \mathrm{rpm}$, no escuro, a $28^{\circ} \mathrm{C}$; B, cultivo estático, no escuro, a $28^{\circ} \mathrm{C}$; e C, cultivo estático, fotoperíodo de $12 \mathrm{~h}$, a $28{ }^{\circ} \mathrm{C}$. Os períodos de incubação para as culturas formadas sob agitação e sob cultivo estático foram de 14 e 21 dias, respectivamente.

Obtenção de extratos e frações cromatográficas: levando em consideração os resultados obtidos no estudo sobre o efeito de condições de cultivo na produção de fitotoxinas, adotou-se o cultivo do fungo em meio de Jenkins-Prior modificado (Fargues et al., 2001) sob as condições de cultivo A, reconhecidas como apropriadas para a produção de fitotoxinas. Após o período de incubação, as culturas foram filtradas em membrana de náilon e papel-filtro Whatman $\mathrm{n}^{\circ} 1$, para remoção de micélio e esporos. O filtrado da cultura foi liofilizado, fornecendo material sólido $(67,68 \mathrm{~g})$, que foi posteriormente ressuspenso em água destilada para um volume final de $1 \mathrm{~L}$. O pH da suspensão foi ajustado para 4,5 por adição de $\mathrm{HCl} 2 \mathrm{~mol} \mathrm{~L}^{-1}$, e a suspensão, extraída com acetato de etila $(3 \times 1 \mathrm{~L})$. O extrato em acetato de etila foi submetido à secagem sobre $\mathrm{MgSO}_{4}$, filtrado e concentrado em evaporador rotatório a $40{ }^{\circ} \mathrm{C}$. O extrato bruto assim obtido $(2,307 \mathrm{~g})$ foi fracionado por cromatografia em coluna de sílica-gel 60 com eluição por gradiente, utilizando hexano-acetato de etila 9:1 (v/v) a 0:1 (v/v). Frações de cerca de $7 \mathrm{~mL}$ foram coletadas em tubos de ensaio e agrupadas de acordo com o perfil em cromatografia em camada delgada. A fração 2 (31 mg), eluída com hexano: acetato de etila 9:1 (v/v), foi submetida a análises por IV e CG-EM.

\section{Ensaios biológicos}

Foram realizados diferentes ensaios biológicos com plântulas e sementes de E. heterophylla. Para investigação preliminar da produção in vitro de fitotoxinas pelos fungos, os filtrados de cultura foram submetidos a ensaios em câmara úmida (Pedras \& Ahiahonu, 2004) e testes de inibição de germinação e crescimento radicular (Macias et al., 2000). Quanto ao fracionamento guiado por bioensaio, foram avaliados os ensaios com punctura de folha (Pedras \& Ahiahonu, 2004) e em folha destacada (Evidente et al., 2008).

Ensaio de inibição de germinação: a fitotoxicidade de filtrados de cultura fúngica contra sementes sadias de $E$. heterophylla foi avaliada segundo metodologia proposta por Macias et al. (2000). Para isso, 25 sementes foram transferidas para placas de Petri $(\varnothing 90 \mathrm{~mm})$ contendo papel de germinação (Germitest $\mathbb{R}$ ) embebido em $5 \mathrm{~mL}$ de filtrado de cultura com Tween 80 a $0,05 \%(\mathrm{~m} / \mathrm{v})$. Filtrados de meios de cultura sem crescimento fúngico contendo Tween 80 a $0,05 \%(\mathrm{~m} / \mathrm{v})$ e água destilada foram utilizados como testemunhas. As placas foram mantidas em câmara climática a $25{ }^{\circ} \mathrm{C}$ e fotoperíodo de $12 \mathrm{~h}$. Após 72 horas, determinaram-se o número de sementes germinadas $\mathrm{e}$ o comprimento das radículas. O delineamento experimental foi o inteiramente casualizado, 
VAREJÃO, E.V.V. et al.

com quatro repetições. Os dados foram submetidos a análise de variância (ANOVA, $p<0,05$ ), e as médias, comparadas pelo teste de Tukey.

Ensaio em câmara úmida: filtrados de cultura contendo Tween 80 a $0,05 \%$ (m/v) foram uniformemente aspergidos sobre folhas sadias de plantas jovens (duas a três semanas) de E. heterophylla cultivadas em casa de vegetação. Filtrados de meios de cultura sem crescimento fúngico contendo Tween 80 a $0,05 \%(\mathrm{~m} / \mathrm{v})$ e solução aquosa de Tween 80 a $0,05 \%(\mathrm{~m} / \mathrm{v})$ foram utilizados como controle. Após aspersão das soluções, as plantas foram mantidas em câmara úmida a $25^{\circ} \mathrm{C}$, e o desenvolvimento dos sintomas foi monitorado, diariamente, por 72 horas. Os sintomas foram convertidos em grau de lesão com o uso de escala arbitrária de intensidade com base em inspeção visual: (-), ausência de sintomas; $(+)$ amarelecimento; $(++)$, necrose $<50 \%$ da área foliar; $(+++)$, necrose $>50 \%$ da área foliar; e $(+++)$, necrose $>50 \%$ da área foliar acompanhada de desfolha.

Ensaio com punctura de folha: soluções das frações cromatográficas $\left(1 \mathrm{mg} \mathrm{mL}^{-1}\right)$ preparadas em $\mathrm{MeOH}$ a $20 \%(\mathrm{~m} / \mathrm{v})$ foram aplicadas sobre puncturas produzidas com auxílio de agulha na superficie adaxial de folhas sadias (duas puncturas por folha) de plântulas jovens (duas a três semanas) de $E$. heterophylla cultivadas em casa de vegetação. Solução metanólica a $20 \%$ (v/v) foi utilizada como controle. O delineamento experimental utilizado foi o inteiramente casualizado, com três repetições. As plântulas foram mantidas em câmara úmida a $25{ }^{\circ} \mathrm{C}$. O aparecimento de sintomas foi monitorado a cada 12 horas, e o diâmetro das lesões, medido após 72 horas.

Ensaio em folha destacada: folhas sadias de plântulas jovens de $E$. heterophyla foram destacadas com auxílio de estilete e pinça e depositadas em placas de Petri contendo papelfiltro umedecido com água destilada (três folhas por placa). Com auxilio de agulha, foram produzidas puncturas sobre a superficie adaxial de cada folha (duas puncturas por folha). Sobre cada lesão, foram depositados $10 \mu \mathrm{L}$ de solução de extratos e frações a $1 \mathrm{mg} \mathrm{mL}^{-1}$ $(\mathrm{m} / \mathrm{v})$, preparadas em $\mathrm{MeOH}$ a $20 \%$ (v/v). As placas foram vedadas e acondicionadas em câmara climática a $25^{\circ} \mathrm{C}$, com fotoperíodo de 12 horas, por 72 horas. O desenvolvimento de sintomas foi observado a cada $12 \mathrm{~h}$, medindose o diâmetro das lesões produzidas após 72 horas. Solução aquosa de $\mathrm{MeOH}$ a 20\% (v/ v) foi utilizada como controle. O delineamento experimental utilizado foi o inteiramente casualizado, com três repetições.

\section{RESULTADOS E DISCUSSÃO}

Para investigação preliminar da capacidade de $A$. euphorbiicola produzir metabólitos fitotóxicos, o fungo foi cultivado em meio de Jenkins-Prior modificado e meio Caldo de Vegetais, incubados nas condições de cultivo A. A escolha dessas condições como ponto de partida para as investigações fundamenta-se em observações realizadas durante estudos sobre o potencial do fungo como bio-herbicida para o manejo de $E$. heterophylla. Nesses estudos, foi observado que a máxima produção de esporos por $A$. euphorbiicola ocorreu após seis a nove dias de cultivo nessas mesmas condições. Após o nono dia, grande quantidade de esporos iniciou a germinação. Diversos trabalhos relatam que a produção de fitotoxinas por diferentes espécies do gênero Alternaria ocorre principalmente durante a germinação de esporos (Slavov et al., 2004; Oka et al., 2005; Parada et al., 2008).

Os filtrados das culturas em meio JenkinsPrior modificado e Caldo de Vegetais inibiram a germinação e o crescimento radicular de sementes de E. heterophylla (Tabela 1), tendo o filtrado do meio Jenkins-Prior apresentado maior atividade. Avaliados em ensaios em câmara úmida, os filtrados de ambos os meios de cultura mostraram atividade fitotóxica contra folhas de $E$. heterophylla (Tabela 2). Os filtrados das testemunhas (meios de cultura sem crescimento fúngico) não produziram sintomas.

Uma vez comprovada a capacidade de produção in vitro de fitotoxinas por A. euphorbiicola, o fungo foi cultivado nos meios Czapek-Dox, de Fries e Jenkins-Prior, e as culturas foram incubadas sob diferentes condições, conforme descrito na seção Material e Métodos. O meio de cultura Caldo de Vegetais foi desconsiderado para esse propósito devido à sua complexa composição química, o que poderia dificultar os trabalhos de isolamento de fitotoxinas. A atividade fitotóxica dos filtrados de culturas 
Tabela 1 - Efeitos de filtrados de culturas de Alternaria euphorbiicola sobre a germinação e crescimento radicular de sementes de Euphorbia heterophylla. Dados em percentual de inibição em relação ao tratamento testemunha (água destilada)

\begin{tabular}{|c|c|c|}
\hline Filtrado & Germinação & $\begin{array}{c}\text { Crescimento } \\
\text { radicular }\end{array}$ \\
\hline JP & $100,0 \mathrm{a}$ & $100,0 \mathrm{a}$ \\
\hline $\mathrm{CV}$ & $50,0 \mathrm{~b}$ & $82,7 \mathrm{~b}$ \\
\hline Controle JP & $0,0 \mathrm{c}$ & $0,0 \mathrm{c}$ \\
\hline Controle CV & $0,0 \mathrm{c}$ & $0,0 \mathrm{c}$ \\
\hline
\end{tabular}

Médias seguidas de letras iguais, na coluna, não diferem pelo teste de Tukey a $5 \%$ de probabilidade. CV: Caldo de Vegetais. JP: JenkinsPrior modificado.

Tabela 2 - Efeitos de filtrados de culturas de Alternaria euphorbiicola sobre folhas de Euphorbia heterophylla em ensaio em câmara úmida

\begin{tabular}{|c|c|c|c|}
\hline \multirow{2}{*}{ Filtrado } & \multicolumn{3}{|c|}{ Condições de cultivo } \\
\cline { 2 - 4 } & $\mathrm{A}$ & $\mathrm{B}$ & $\mathrm{C}$ \\
\hline $\mathrm{CV}$ & +++ & $\mathrm{nt}$ & $\mathrm{nt}$ \\
\hline $\mathrm{JP}$ & ++++ & +++ & - \\
\hline $\mathrm{Cz}$ & - & - & - \\
\hline $\mathrm{MF}$ & ++ & ++ & - \\
\hline
\end{tabular}

CV: Caldo de Vegetais; JP: Jenkins-Prior modificado; Cz: CzapekDox; MF, meio de Fries. Sintomas convertidos em grau de lesão por meio de escala arbitrária, com base em inspeção visual: (-) ausência de sintomas; $(+)$ amarelecimento; $(++)$, necrose $<50 \%$ da área foliar; $(+++)$, necrose $>50 \%$ da área foliar; e $(++++)$, necrose $>50 \%$ da área foliar e desfolha. nt: não testado.

obtidos foi avaliada em experimento em câmara úmida (Tabela 2). Os filtrados das culturas formadas em meio Czapek-Dox não produziram sintomas nas folhas de E. heterophylla. Os filtrados das culturas formadas em meio de Fries produzidas no escuro, tanto sob cultivo estático quanto sob agitação (condições A e B), produziram amarelecimento e necrose em folhas da planta, enquanto o filtrado da cultura crescida neste meio sob fotoperíodo de 12 horas (condição C) não produziu sintomas observáveis até 72 horas após aplicação. Da mesma forma, o filtrado da cultura formada em meio JenkinsPrior modificado sob fotoperíodo (condição C) não produziu sintomas. A maior atividade fitotóxica foi observada nos filtrados de culturas formadas no meio Jenkins-Prior modificado e mantidas sob agitação (condição A). Entre os meios de cultura testados, o Czapek-Dox é o que apresenta composição mais simples, enquanto o meio de Jenkins-Prior modificado é o mais complexo e rico em nutrientes. Como os filtrados das culturas em Czapek-Dox não apresentaram fitotoxicidade e os filtrados do meio de Jenkins-Prior foram os mais ativos, pode-se concluir que a produção de fitotoxinas pelo fungo está diretamente condicionada por fatores nutricionais. Ainda, os resultados permitiram observar que o cultivo na ausência de luz e sob agitação favorece a produção de fitotoxinas por A. euphorbiicola.

Vários estudos demonstraram a influência das condições de cultivo sobre a biossintese in vitro de compostos fitotóxicos por fungos fitopatogênicos. Foi observada influência do meio de cultura na produção de ácido fusárico por Fusarium oxysporum f. sp. litii. Cultivado em quatro meios distintos, a $23{ }^{\circ} \mathrm{C}$ e sob agitação (100 rpm), o fungo produziu maiores quantidades da toxina em meio Czapek Dox (Löffler $\&$ Mouris, 1992). O cultivo estacionário ou sob agitação pode influenciar a produção de toxinas. Brzonkalik et al. (2011) demonstraram que o cultivo estático de Alternaria alternata levou à produção de maiores quantidades das toxinas alternariol, alternariol metil éter e ácido tenuazônico, quando comparado ao cultivo sob agitação. A investigação da influência das condições de cultivo sobre a produção da fitotoxina cercosporina por diferentes espécies do gênero Cercospora mostrou que a composição do meio de cultura, a temperatura e o cultivo sob iluminação ou no escuro exerceram influência na produção da toxina por todas as espécies avaliadas (Jenns et al., 1989).

Diante dos resultados obtidos, para fins de produção, isolamento e identificação de toxinas, o fungo foi cultivado em meio de JenkinsPrior modificado, sob a condição de cultivo A. Os filtrados de cultura obtidos foram liofilizados e ressuspensos em água destilada para volume final de $1 \mathrm{~L}$. A suspensão foi extraída com acetato de etila, e o extrato bruto, assim obtido, submetido a ensaios com punctura de folha e em folha destacada. Esses ensaios foram considerados para o direcionamento dos trabalhos de fracionamento do extrato por requererem pequenas quantidades de extratos e frações, além de permitirem avaliações quantitativas mais precisas, quando comparados à aspersão de soluções sobre folhas. Quando 
aplicado sobre puncturas produzidas na superficie de folhas destacadas, o extrato orgânico bruto produziu halos de clorose e necrose com 1,4 mm de diâmetro, em média. Os sintomas necróticos tornaram-se visíveis após 48 horas. Quando aplicados sobre folhas na planta (ensaio com punctura de folhas), halos necróticos com 2,8 mm de diâmetro, em média, foram observados em menos de 24 horas após aplicação. Dada a maior sensibilidade e rapidez no desenvolvimento de sintomas nos ensaios em plantas vivas, o ensaio com punctura de folhas foi selecionado para guiar o fracionamento do extrato. A solução metanólica a $20 \%$ (v/v), utilizada como controle, não produziu lesão. O extrato orgânico bruto foi submetido a cromatografia em coluna de sílica, fornecendo uma fração (fração 3) capaz de produzir, a $1 \mathrm{mg} \mathrm{mL}{ }^{1}$, halos cloróticos com bordas necrosadas com 3,5 mm de diâmetro, em média (Figura 1).

A análise da fração 3 por espectroscopia no infravermelho mostrou um espectro de absorção (Figura 2) característico de ácidos carboxílicos de cadeia longa, com bandas de absorção em $2.923\left(v_{\text {as }} \mathrm{CH}_{3}\right), 2.853\left(v_{\mathrm{s}} \mathrm{CH}_{2}\right)$, $1.707(v \mathrm{C}=\mathrm{O}), 1.462\left(\delta_{\mathrm{s}} \mathrm{CH}_{2}\right.$ e $\left.\delta_{\text {as }} \mathrm{CH}_{3}\right), 1.414$ (combinação de $v \mathrm{C}-\mathrm{O}$ e $\delta \mathrm{OH}), 1.264\left(\delta_{\mathrm{s}} \mathrm{CH}_{3}\right)$,

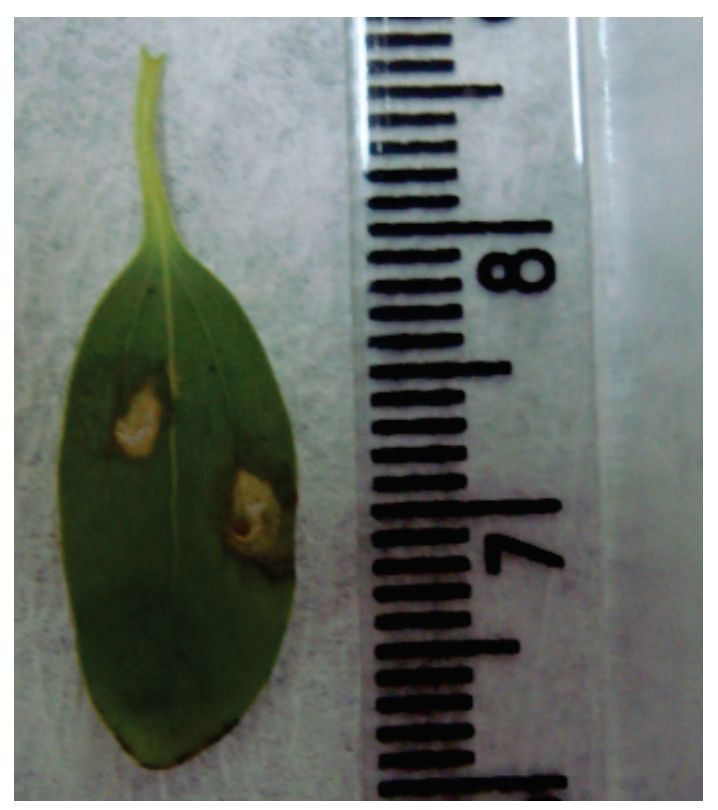

Figura 1 - Lesões necróticas produzidas pela aplicação de solução da fração cromatográfica $3\left(1 \mathrm{mg} \mathrm{mL}^{-1}\right)$ sobre folhas de Euphorbia heterophylla.

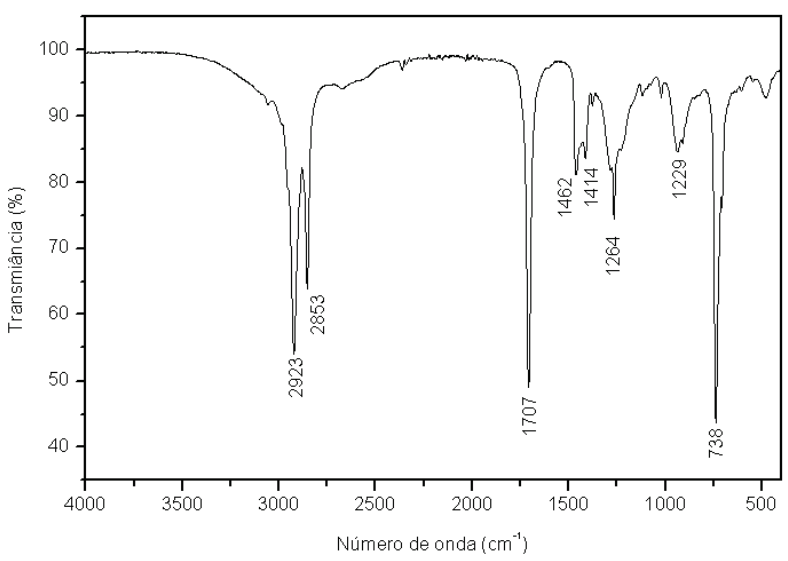

Figura 2 - Espectro no infravermelho (sólido) da fração cromatográfica caracterizada.

1.229 ( $v \mathrm{C}-\mathrm{O}$ ) e $738 \mathrm{~cm}^{-1}\left(\rho \mathrm{CH}_{2}\right)$ (Figura 1). A análise por CG-EM (Figura 2) resultou na caracterização dos ácidos graxos mirístico $(2,6 \%)$, palmitoleico $(2,1 \%)$, palmítico $(38,5 \%)$, oleico $(37,5 \%)$, esteárico $(3,2 \%)$, erucico $(4,2 \%)$ e do álcool graxo 9-octadecen-1-ol (10,5\%) (Figura 3).

A atividade fitotóxica de ácidos graxos de cadeia longa tem sido demonstrada em diferentes estudos. O fracionamento de extrato em acetato de etila de cultura do fungo Corynespora cassiicola em meio sólido forneceu frações cromatográficas capazes de produzir inibição da sintese de ATP em cloroplastos isolados de espinafre. Análises por IV e CG-EM levaram à caracterização dos ácidos mirístico, palmítico, palmitoleico, linoleico, esteárico, linolênico e aracnídico (Passos et al., 2010).

Diversos ácidos graxos de cadeia longa entre eles o palmítico, o esteárico, o mirístico e o oleico - são capazes de inibir a germinação de sementes de diferentes espécies (Lynch, 1980; Marambe et al., 1993). Esses ácidos foram capazes de provocar diminuição da atividade da $\alpha$-amilase e redução de ATP em sementes de sorgo (Marambe et al., 1993).

Ainda, estudos demonstraram que vários ácidos graxos de cadeia média (C8 a C14) foram capazes de causar descoloração de folhas, murcha e morte de diferentes espécies de plantas, dentro de um a dois dias após aplicação (Fukuda et al., 2004). O estudo demonstrou ainda que os ácidos graxos, especialmente C9, $\mathrm{C} 10$ e $\mathrm{C} 11$, foram capazes de produzir dano 


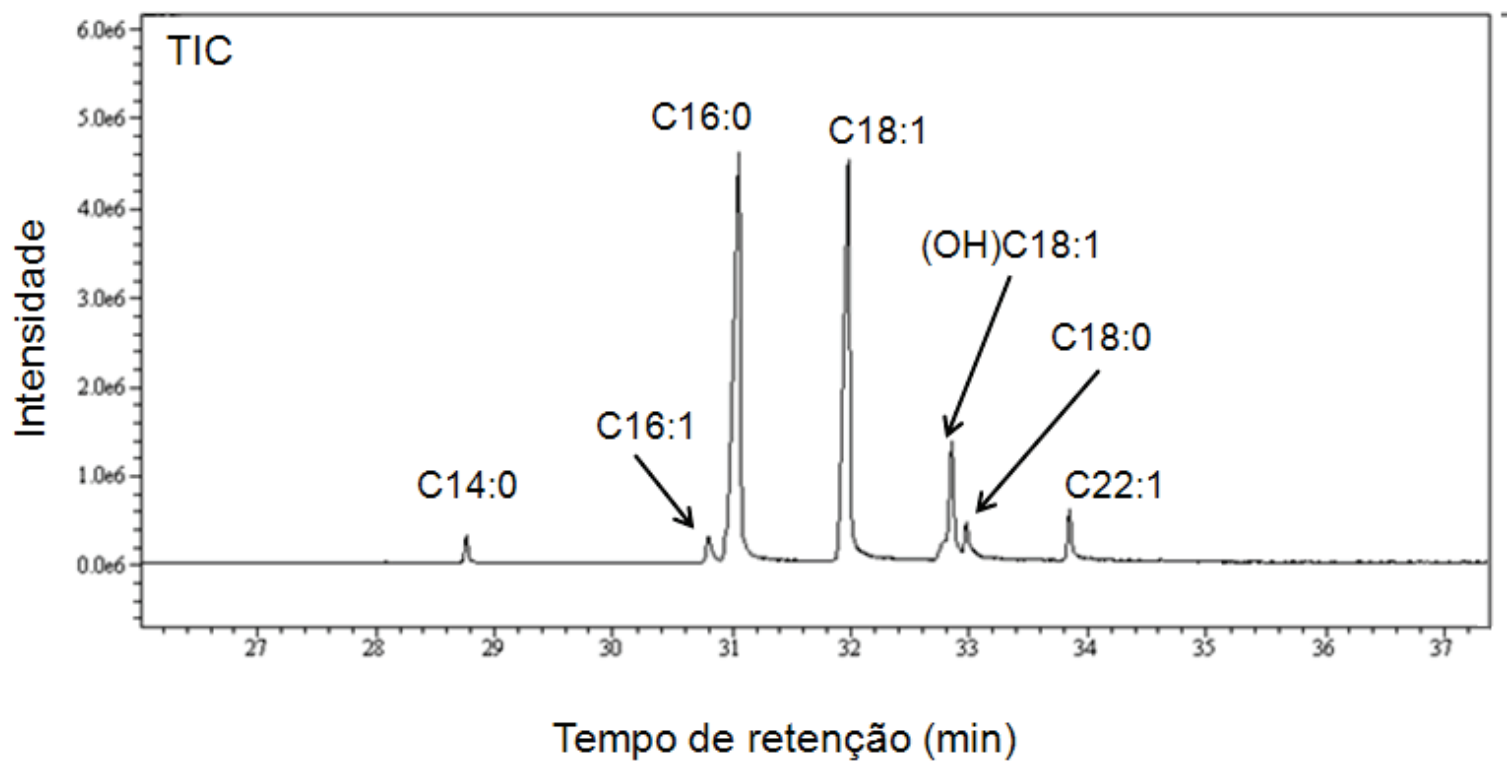

Figura 3 - Cromatograma de íons totais da fração 3. C14:0 (ácido mirístico); C16:1 (ácido palmitoleico); C16:0 (ácido palmítico); C18:1 (ácido oleico); (OH)C18:1 (9-octadecen-1-ol); C18:0 (ácido esteárico); e C22:1 (ácido erucico).

a membranas celulares, induzir perda de eletrólitos e causar decréscimo da quantidade de clorofila. Segundo Lederer et al. (2004), a atividade fitotóxica desses ácidos graxos também se deve à capacidade de induzir peroxidação lipídica.

Os estudos sobre a atividade de filtrados de cultura de A. euphorbiicola contra $E$. heterophylla resultaram na caracterização de uma fração cromatográfica fitotóxica constituída principalmente por ácidos graxos, cujas atividades fitotóxicas já foram relatadas em diferentes trabalhos. A capacidade de inibir a sintese de ATP, de provocar diminuição do teor de clorofila e de induzir peroxidação lipídica, observada em trabalhos anteriores, é um mecanismo de ação que pode justificar o amarelecimento produzido sobre folhas de $E$. heterophylla pelos ácidos graxos identificados na fração. Como o amarelecimento de folhas constitui o primeiro sintoma observado após a inoculação do fungo na planta hospedeira, os resultados deste trabalho sugerem a participação desses ácidos graxos no processo de invasão de tecidos da planta pelo fungo e justificam estudos adicionais sobre essas substâncias, visando a sua avaliação para o desenvolvimento de herbicidas naturais para E. heterophylla.

\section{AGRADECIMENTOS}

Ao Conselho Nacional de Desenvolvimento Científico e Tecnológico (CNPq), pelas bolsas de pesquisa (LCAB, AJD, RWB), e à Coordenação de Aperfeiçoamento de Pessoal de Nível Superior (CAPES).

\section{LITERATURA CITADA}

BARBOSA, L. C. A. et al. Synthesis and phytotoxic activity evaluation of new oxygenated analogues of helminthosporic acid. Química Nova, v. 26, n. 5, p. 655-660, 2003.

BARBOSA, L. C. A. et al. Synthesis and phytogrowth properties of oxabicyclic analogues related to helminthosporin. Molecules, v. 14, n. 1, p. 160-173, 2009.

BARRETO, R. W.; EVANS, H. Fungal pathogens of Euphorbia heterophylla and E. hirta in Brazil and their potential as weed biocontrol agents. Mycopathologia, v. 141, n. 1, p. 31-26, 1998.

BEADLE, G. W.; TATUM, E. L. Genetic control of biochemical reactions in Neurospora. Proc. Nat. Acad. Sci. USA, v. 27, n. 11, p. 499-506, 1941.

BERESTETSKYI, O. A review of fungal phytotoxins: from basic studies to practical use. Appl. Biochem. Microbiol., v. 44, n. 5 , p. $453-465,2008$ 
BRZONKALIK, $\mathrm{K}$. et al. The influence of different nitrogen and carbon sources on mycotoxin production in Alternaria alternata. Inter. J. Food Microbiol., v. 147, n. 2, p. 120-126, 2011.

CARVALHO, L. B. et al. Interferência de Euphorbia heterophylla no crescimento e acúmulo de macronutrientes da soja. Planta Daninha, v. 28, n. 1, p. 33-39, 2010.

CERDEIRA, A. L. et al. Agricultural impacts of glyphosateresistant soybean cultivation in South America. J. Agric.

Food Chem., v. 59, n. 11, p. 5799-5807, 2011.

CHAVES, F. C. et al. New helminthosporal analogues with plant-growth regulatory properties synthesized via oxallyl cation. Z. Naturforsch B, v. 61, n. 10, p. 1287-1294, 2006.

CHEN, W-Q.; SWART, W. J. The in vitro phytotoxicity of culture filtrates of Fusarium oxysporum to five genotypes of Amaranthus hybridus. Euphytica, v. 127, n. 1, p. 61-67, 2002.

CURY, J. P. et al. Produção e partição de matéria seca de cultivares de feijão em competição com plantas daninhas Planta Daninha, v. 29, n. 1, p. 149-158, 2011.

DEMUNER, A. J. et al. Phytotoxic constituents from Nimbya alternantherae. Biochem. Syst. Ecol., v. 34, n. 11, p. 790-795, 2006.

DUKE, S. O. et al. Chemicals from nature for weed management. Weed Sci., v. 50, n. 2, p. 138-151, 2002.

EVIDENTE, A. et al. Phyllostictines A - D, Oxazatricycloalkenones produced by Phyllosticta cirsii, a potential mycoherbicide for Cirsium arvense biocontrol. Tetrahedron, v. 64, n. 8, p. 1612-1619, 2008.

FARGUES, J. Effect of liquid culture media on morfology, growth, propagule production, and pathogenic activity of the Hyphomycete, Metarhizium flavoviride. Mycopathologia, v. 15 , n. 3 , p. $127-138,2001$

FUKUDA, M. et al. Phytotoxic activity of middle-chain fatty acids I: effects on cell constituents. Pest. Biochem. Physiol., v. 80, n. 3, p. 143-150, 2004.

GAZZIERO, D. L. P. et al. Resistência de amendoim-bravo aos herbicidas inibidores da enzima ALS. Planta Daninha, v. 16, n. 2 , p. $117-125,1998$

HOAGLAND, R. E. Microbial allelochemicals and pathogens as bioherbicidal agents. Weed Technol., v. 15, n. 4, p. 835857, 2001.

JENNS, A. E. et al. Regulation of cercosporin accumulation in culture by medium and temperature manipulation. Physiol Biochem., v. 79, n. 2, p. 213-219, 1989.
LEDERER, B. et al. Phytotoxic activity of middle-chain fatty acids II: peroxidation and membrane effects. Pest. Biochem. Physiol., v. 80, n. 3, p. 151-156, 2004.

LÖFFLER, H. J. M.; MOURIS, J. R. Fusaric acid: phytotoxicity and in vitro production by Fusarium oxysporum f.sp. lili, the causal agent of basal rot in lilies. Neth. J. Plant Pathol., v. 98, n. 2, p. 107-115, 1992

LINSTROM, P. J.; MALLARD, W. G. NIST Chemistry WebBook., Gaithersburg: National Institute of Standards and Technology, 2005. (NIST Standard Reference Database Number 69). Disponível em: <http://webbook.nist.gov/ chemistry>. Acesso em: 22 set. 2011.

LYNCH, J. M. Effects of organic acids on the germination of seeds and growth of seedlings. Plant Cell Environ., v. 3, n. 4, p. 255-259, 1980.

MACÍAS, F. A. et al. Search for a standard phytotoxic bioassay for allelochemicals. Selection of standard target species. J. Agric. Food Chem., v. 48, n. 6, p. 2512-2521, 2000 .

MARAMBE, B. et al. Identification and biological activity of germination-inhibiting long-chain fatty acids in animal-waste composts. Plant Cell Physiol., v. 34, n. 4, p. 605-612, 1993.

MÖBIUS, N.; HERTWECK, C. Fungal phytotoxins as mediators of virulence. Current Op. Plant Biol., v. 12, n. 4, p. $390-398,2009$.

OKA, K. et al. Host-specific AB-toxin production by germinating spores of Alternaria brassicicola is induced by a host-derived oligosaccharide. Physiol. Molec. Plant Pathol., v. 66, n. 1, p. 12-19, 2005.

PARADA, R. Y. et al. Alternaria brassicae produces a hostspecific protein toxin from germinating spores on host leaves. Biochem. Cell Biol., v. 98, n. 4, p. 258-263, 2008.

PASSOS, J. L. et al. Efeitos de Corynespora cassiicola sobre Lantana camara. Planta Daninha, v. 28, n. 2, p. 229-237, 2010.

PEDRAS, M. S. C.; AHIAHONU, P. W. K. Phytotoxin production and phytoalexin elicitation by the phytopathogenic fungus Sclerotinia sclerotiorum. J. Chem. Ecol., v. 30, n. 11, p. 2163-2179, 2004.

PEREIRA, J. M. et al. Corynespora cassiicola f. sp. lantanae a potential biocontrol agent for Lantana camara from Brazil. Biol. Control, v. 26, n. 1, p. 21-31, 2003.

RIZZARDI, M. A. et al. Interferência de populações de Euphorbia heterophylla e Ipomoea ramosissima isoladas ou em misturas sobre a cultura de soja. Planta Daninha, v. 22, n. 1, p. 29-34, 2004 
SLAVOV, S. et al. Toxin production of Alternaria alternata tobacco pathotype. Biotechnol. Biotechnol Equip., v. 18, n. 3, p. $90-95,2004$

SOUZA FILHO, A. P. S.; DUARTE, M. L. R. Atividade alelopática do filtrado de cultura produzido por Fusarium solani. Planta Daninha, v. 25, n. 1, p. 227-230, 2007.

STRANGE, R. N. Phytotoxins produced by microbial plant pathogens. Nat. Prod. Rep., v. 24, n. 1, p. 127-144, 2007.
TREZZI, M.M et al. Multiple resistance of acetolactate synthase and protoporphyrinogen oxidase inhibitors in Euphorbia heterophylla biotypes. J. Environ. Sci. Health, v. 40, n. 1, p. 101-109, 2005

VIDAL, R. A. et al. Glyphosate resistant biotypes of wild poinsettia (Euphorbia heterophylla (L.)) and its risk analysis on glyphosate-tolerant soybeans. J. Food Agric. Environ., v. 5 , n. 2 , p. $265-269,2007$. 